\title{
3,5-Diiodo-L-thyronine modulates the expression of genes of lipid metabolism in a rat model of fatty liver
}

\author{
Elena Grasselli ${ }^{1}$, Adriana Voci ${ }^{1}$, Ilaria Demori ${ }^{1}$, Laura Canesi ${ }^{1,5}$, Rita De Matteis ${ }^{2}$, Fernando Goglia ${ }^{3}$, \\ Antonia Lanni ${ }^{4}$, Gabriella Gallo ${ }^{1}$ and Laura Vergani ${ }^{1,5}$ \\ ${ }^{1}$ DIPTERIS, Università di Genova, Genova, Italy \\ ${ }^{2}$ Dipartimento di Scienze Biomolecolari, Università di Urbino, Urbino, Italy \\ ${ }^{3}$ Dipartimento di Scienze Biologiche ed Ambientali, Università del Sannio, Benevento, Italy \\ ${ }^{4}$ Dipartimento di Scienze della Vita, Seconda Università di Napoli, Caserta, Italy \\ ${ }^{5}$ Istituto Nazionale Biostrutture e Biosistemi (INBB), Rome, Italy \\ (Correspondence should be addressed to G Gallo; Email: unige.physiology@gmail.com)
}

\begin{abstract}
Recent reports demonstrated that 3,5-diiodo-L-thyronine $\left(\mathrm{T}_{2}\right)$ was able to prevent lipid accumulation in the liver of rats fed a high-fat diet (HFD). In this study, we investigated how the rat liver responds to HFD and $T_{2}$ treatment by assessing the transcription profiles of some genes involved in the pathways of lipid metabolism: oxidation, storage and secretion. The mRNA levels of the peroxisome proliferator-activated receptors (PPAR $\alpha, \operatorname{PPAR} \gamma$ and PPAR $\delta$ ), and of their target enzymes acyl-CoA oxidase and stearoyl-CoA desaturase were evaluated by real-time RT-PCR. Moreover, the expression of the adipose triglyceride lipase involved in lipid mobilisation, of the main PAT proteins acting in lipid droplet (LD) turnover, and of apoprotein B (apo B), the major
\end{abstract}

protein component of very low-density lipoproteins (VLDLs) were analysed. Overall, our data demonstrated that $T_{2}$ administration to HFD rats counteracts most of the hepatic transcriptional changes that occurred in response to the excess exogenous fat. In particular, our results suggest that $T_{2}$ may prevent the pathways leading to lipid storage in LDs, promote the processes of lipid mobilisation from LDs and secretion as VLDL, in addition to the stimulation of pathways of lipid oxidation. In conclusion, our findings might give an insight into the mechanisms underlying the anti-steatotic ability of $T_{2}$ and help to define the potential therapeutic role of $T_{2}$ for preventing or treating liver steatosis.

Journal of Endocrinology (2012) 212, 149-158

\section{Introduction}

Hepatic steatosis refers to an excess accumulation of lipids, primarily triglycerides (TAGs) and it is a major element of non-alcoholic fatty liver disease (NAFLD; Unger et al. 2010). Lipid metabolism is mainly regulated by the peroxisome proliferator-activated receptors (PPARs), a subfamily of lipid-activated transcription factors, consisting of three members, PPAR $\alpha, \operatorname{PPAR} \gamma$ and $\operatorname{PPAR} \delta$, with distinct functional roles (Viswakarma et al. 2010, Wanders et al. 2010). In the liver, PPAR $\alpha$ is the master regulator of free fatty acid (FFA) oxidation systems, and decreases FFA efflux (Reddy 2001, Pyper et al. 2010). Also PPAR $\delta$ induces expression of genes required for FFA oxidation (Evans et al. 2004, Pyper et al. 2010). Conversely, PPAR $\gamma$ is mainly expressed in adipose tissue, but it promotes lipid accumulation also in hepatocytes where it plays anti-inflammatory effects by both reducing inflammatory cytokine and chemokine expression and preventing the activation of pro-inflammatory transcription factors (Delerive et al. 2001, Straus \& Glass
2007, Kapadia et al. 2008). In summary, PPAR $\alpha$ and PPAR $\delta$ mainly participate in energy burning, whereas PPAR $\gamma$ is critical in regulating energy storage (Musso et al. 2009), even though an overlapping in their function has been widely reported.

Excess TAGs are stored under form of cytosolic lipid droplets (LDs) regulating storage and traffic of lipids (for a review see Ducharme \& Bickel (2008) and Olofsson et al. (2009)). Typically, LDs exhibit a core of TAGs and cholesteryl esters surrounded by a phospholipid monolayer that contains numerous proteins including the 'PAT proteins' with structural, regulatory or enzymatic functions (Bickel et al. 2009). A previous study of our group (Grasselli et al. 2010) showed that, in rat hepatocytes, lipid overload was associated with altered expression of three PAT proteins: the adipocyte differentiation-related protein (ADRP, also called PLIN2), the oxidative tissue-enriched PAT protein (OXPAT or PLIN5) and the tail-interacting protein (TIP47 or PLIN3; Kimmel et al. 2010), which are thought to be involved in LD turnover together with the endoplasmic reticulum (ER) 
resident protein fat-inducing transcript 2 (FIT2; Kadereit et al. 2008, Sun et al. 2010).

In the liver, TAGs stored in LDs may be mobilised by lipases that trigger FFAs either for oxidation or for secretion as very low-density lipoproteins (VLDLs). The relative abundance of PAT proteins on LDs is decisive for the regulation of the action of lipases (Zimmermann et al. 2009). Recently, discovered adipose triglyceride lipase (ATGL) selectively performs the first step in TAG hydrolysis (Duncan et al. 2007, Zechner et al. 2009), and is constitutively expressed in the liver of mammals (Reid et al. 2008).

To be secreted by the liver through exocytosis, TAGs must be packaged together with apoprotein B (apo B), the major protein component of VLDL (Vance \& Vance 1990). Recent studies have pointed out that hepatic secretion of VLDL is increased during NAFLD, even though it seems to be inadequate to match the increased TAG availability (Zivkovic et al. 2007).

Thyroid hormones (THs) are major modulators of energy homeostasis, and their role in lipid metabolism has supported their potential use as drugs to promote weight loss. Several evidences suggested that 3,5-diiodo-L-thyronine $\left(\mathrm{T}_{2}\right)$, a naturally occurring iodothyronine, mimics several effects of 3,3',5-L-triiodothyronine $\left(\mathrm{T}_{3}\right)$ on energy metabolism without inducing thyrotoxic effects (Lanni et al. 1994, Cimmino et al. 1996, Lombardi et al. 1998). Also $\mathrm{T}_{2}$, like $\mathrm{T}_{3}$, is able to stimulate both resting metabolic rate and mitochondrial activity in hypothyroid rats (Moreno et al. 1997). However, although it is likely that iodothyronines regulate energy metabolism by both short- and long-term actions, the molecular mechanisms are still unclear (Goglia 2005). Moreover, long-term administration of $\mathrm{T}_{2}$ to rats fed highfat diet (HFD) was able to counteract the body weight (BW) and fat mass gain, as well as lipid accumulation and oxidative stress in the liver (Lanni et al. 2005, Grasselli et al. 2008). $T_{2}$ affects liver metabolism by increasing mitochondrial FFA oxidation and mitochondrial uncoupling (Lanni et al. 2005, Grasselli et al. 2008), but exerts metabolic effects also in skeletal muscle by increasing mitochondrial oxidative capacity (Lombardi et al. 2007). In a recent study (Grasselli et al. $2011 b$ ), we demonstrated that the lipid-lowering effect of both $\mathrm{T}_{2}$ and $\mathrm{T}_{3}$ occurs via non-receptor-mediated mechanisms that seem to involve both a short-term action by stimulation of mitochondrial $\mathrm{O}_{2}$ consumption, and a longterm action by differential transcriptional effects on PPARs.

In the attempt to clarify the mechanisms underlying the anti-steatotic ability of $\mathrm{T}_{2}$ better, in this study we analysed the mRNA expression of several genes involved in three processes of lipid metabolism in the rat liver: oxidation, storage and secretion. Using a validated in vivo model of fatty liver, we show that HFD induces the expression of genes of lipid storage and catabolism, whereas $T_{2}$ prevents these changes. At the same time, $T_{2}$ stimulates mechanisms of FFA oxidation and lipid secretion thus ameliorating the status of hepatic steatosis as well as the pre-inflammatory condition induced by HFD.

\section{Materials and Methods}

\section{Chemicals}

All chemicals, unless otherwise indicated, were of analytical grade and were obtained from Sigma-Aldrich Corp.

\section{Animals and treatments}

Animal maintenance and treatment were carried out according to the guidelines of the European Community Council for animal care and use, as described elsewhere (Grasselli et al. 2008). Briefly, 24 male Wistar rats (Harlan, San Pietro al Natisone, Italy), housed in individual cages, were randomly divided into four groups (each group, six animals). In each group, BW was normally distributed, and BW means were similar for all animals. The first group (C) received a standard diet $(15.88 \mathrm{~kJ}$ gross energy/g); the second group (D) was fed a HFD (19.85 kJ gross energy/g); the third group (DT) received the same HFD and a simultaneous daily i.p. injection of $\mathrm{T}_{2}(25 \mu \mathrm{g} / 100 \mathrm{~g} \mathrm{BW})$; and the fourth group (CT) received a standard diet and a simultaneous daily i.p. injection of $\mathrm{T}_{2}(25 \mu \mathrm{g} / 100 \mathrm{~g} \mathrm{BW})$. C and D rats were daily i.p. injected with the same volume of physiological saline solution. After 30 days of treatment, rats were anesthetised and killed by cervical dislocation. Before blood and tissue sampling, rats were not fasted to avoid possible interference with the effects of HFD. Blood was collected and serum concentrations of TAGs, cholesterol and glucose were measured using a Hitachi 7170 clinical analyser (Hitachi) by following standard procedures. Immediately after death, livers were rapidly dissected, weighed, cut into small pieces, quickly frozen in liquid nitrogen and stored at $-80{ }^{\circ} \mathrm{C}$ until use.

\section{Liver morphological analysis and lipid staining}

To detect fat accumulation in the livers, frozen tissue sections were stained with Oil Red O (ORO) according to the method described by Koopman et al. (2001). Briefly, liver cryosections were fixed in 10\% formalin at room temperature for $15 \mathrm{~min}$, then dipped in $70 \%$ isopropanol for $3 \mathrm{~min}$. Afterwards, slides were immersed in 1\% ORO solution for $15 \mathrm{~min}$, washed first in 70\% isopropanol then in distilled water, and mounted using aqueous mounting medium.

Haematoxylin-eosin staining of liver sections was done using standard protocols (Grasselli et al. 2011a). Livers were fixed, dehydrated, embedded in paraffin, sectioned $(8 \mu \mathrm{m})$ and stained with haematoxylin-eosin. Slides were examined by Nikon Eclipse E80i light microscope (Nikon, Japan).

\section{Immunohistochemical staining for $A D R P$}

Paraffin-embedded liver sections $(4 \mu \mathrm{m})$ were incubated with anti-ADRP polyclonal antibody (clone GP40-mN1, Fitzgerald Industries International, Concord, MA, USA). The immunoreaction was detected with the avidin-biotin-peroxidase 
complex (ABC) method (Hsu et al. 1981) using $\mathrm{ABC}$ Vectastain-Elite Kit (Vectastain ABC Elite Kit, Vector Labs, Burlingame, CA, USA), as described previously (Grasselli et al. 2011a). The liver sections were counterstained with haematoxylin to reveal nuclei and mounted in Eukitt (Kindler, Freiburg, Germany). Omission of the primary antibody served as negative control.

\section{$R N A$ extraction and quantitative RT-PCR}

Total RNA was extracted from aliquots of frozen pooled tissues from each experimental group by Trizol Reagent (Sigma-Aldrich) according to the manufacturer's instructions. First-strand cDNA was synthesised from $2 \mu \mathrm{g}$ of total RNA using 200 RevertAid H-Minus M-MuLV Reverse Transcriptase (Fermentas, Hannover, MD, USA) $200 \mathrm{ng}$ oligo(dT)18-mer, 1 mM dNTPs (Invitrogen), $100 \mathrm{U}$ RNase inhibitor (Fermentas), as described elsewhere (Grasselli et al. 2011b). Quantitative RT-PCR (RT-qPCR) was performed in quadruplicate in a final volume of $25 \mu$ containing $0 \cdot 3 \mu \mathrm{M}$ of each primer, 10 ng cDNA, $1 \times$ SybrGreen PCR Master Mix and were analysed in 96-well optical reaction by $7900 \mathrm{HT}$ fast real-time PCR system (Applied Biosystems, Monza, Italy) by the thermal protocol described previously (Vergani et al. 2011). Primers were synthesised by TibMolBiol custom oligosynthesis service (Genova, Italy). Primers (Table 1) were designed ad hoc starting from the coding sequences of Rattus norvegicus available on the GenBank database (http://www. ncbi.nlm.nih.gov/Genbank/GenbankSearch.html). A melting curve of RT-PCR products $\left(55-94^{\circ} \mathrm{C}\right)$ was also performed to ensure the absence of artefacts. The quantification cycle $\left(\mathrm{C}_{\mathrm{q}}\right)$ represents the cycle number at which the amount of amplified target reaches the fixed threshold (Bustin 2010). The relative quantity of target mRNA was calculated by the comparative $\mathrm{C}_{\mathrm{q}}$ method and was normalised for the expression of Gapdh gene (Pfaffl 2001). The normalised expression was thus expressed as relative quantity of mRNA (fold induction) with respect to controls (C).

\section{Statistical analysis}

Data on RT-qPCR are means \pm s.D. of three independent RNA extractions performed in quadruplicate. Enzyme activities are means \pm S.D. of three independent experiments performed in triplicate. Statistical analysis was performed by ANOVA followed by Bonferroni post-hoc test (Instat Software, GraphPad Software, Inc., San Diego, CA, USA).

\section{Results}

\section{Liver lipid accumulation, histology and inflammation}

Table 2 summarises BW gain and serum values of TAGs, cholesterol and glucose in control rats (C), HFD-fed rats (D),

Table 1 Characteristics of the primer pairs used for quantitative RT-PCR analysis

\begin{tabular}{|c|c|c|c|c|c|}
\hline $\begin{array}{l}\text { Primer names } \\
\quad \text { (gene names) }\end{array}$ & Primer sequences $\left(5^{\prime} \rightarrow 3^{\prime}\right)$ & $\begin{array}{c}\text { Annealing } \\
\text { temperature }\left({ }^{\circ} \mathrm{C}\right)\end{array}$ & $\begin{array}{l}\text { Product } \\
\text { length (bp) }\end{array}$ & Accession ID & References \\
\hline GAPDH & F: GACCССТTCATTGACСТCAAC & 60 & 136 & DQ403053 & Grasselli et al. (2008) \\
\hline (Gapdh) & R: CGCTCCTGGAAGATGGTGATGGG & & & & \\
\hline IL1 $\beta$ & F: AGGCATAACAAGCTCATCTGGG & 56 & 176 & NM_031512 & This work \\
\hline$(/ / 1 b)$ & R: CATCTGGACAGCCCAAGTCAAGG & & & & \\
\hline $\operatorname{PPAR} \alpha$ & F: CCCCACTTGAAGCAGATGACC & 60 & 139 & NM_013196 & Grasselli et al. (2011a) \\
\hline (Ppara) & R: CCCTAAGTACTGGTAGTCCGC & & & & \\
\hline PPAR $\delta$ & F: AATGCCTACCTGAAAAACTTCAAC & 60 & 96 & AJ306400.1 & Grasselli et al. (2011a) \\
\hline (Ppard) & R: TGCCTGCCACAGCGTCTCAAT & & & & \\
\hline $\operatorname{PPAR} \gamma$ & F: CGGAGTCCTCCCAGCTGTTCGCC & 60 & 116 & Y12882 & Grasselli et al. (2011a) \\
\hline (Pparg) & R: GGCTCATATCTGTCTCCGTCTTC & & & & \\
\hline SCD-1 & F: CACACGCCGACССТСАСААСТ & 60 & 97 & AF509569 & Grasselli et al. $(2011 b)$ \\
\hline$\left(S_{c d 1}\right)$ & R: TCCGCCСТTCTCTTTGACAGCC & & & & \\
\hline AOX & F: GCGCAAGGAGCGGGCCTCC & 64 & 84 & AAA40666 & This work \\
\hline$(A C O X)$ & R: CTCGACGGCGCCGGGTATTC & & & & \\
\hline ATGL & F: CGGTGGATGAAGGAGCAGACA & 60 & 137 & NM_001108509 & Romero et al. (2009) \\
\hline (Pnpla2) & R: TGGCACAGACGGCAGAGACT & & & & \\
\hline ADRP & F: CCGAGCGTGGTGACGAGGG & 60 & 148 & AAH85861 & Grasselli et al. (2010) \\
\hline (Plin2) & R: GAGGTCACGGTCCTCACTCCC & & & & \\
\hline OXPAT & F: GGATGTCCGGTGATCAGAC & 60 & 96 & XM_576698 & Grasselli et al. (2010) \\
\hline$($ Plin5) & R: GTGCACGTGGCCСTGACCAG & & & & \\
\hline TIP47 & F: GGAACTGGTGTCATCAACAG & 60 & 108 & 316130 & Grasselli et al. (2010) \\
\hline (Plin3) & R: GGTCACATCCACTGСТССТG & & & & \\
\hline Fit2 & F: AAGGGGGCTTCTGGTACGGCT & 60 & & NM_001107799.1 & This work \\
\hline (Fitm2) & R: TGGCTGCGATCTGTCTTCACC & & & & \\
\hline Apo B & F: CGTGGGCTCCAGCATTCTA & 60 & 71 & NM_019287.2 & Spann et al. (2006) \\
\hline$(A p o b)$ & R: TCACCAGTCATTTCTGCCTTTG & & & & \\
\hline
\end{tabular}

$F$, forward; $R$, reverse. 
Table 2 Effects of high-fat diet (HFD) and 3,5-diiodo-L-thyronine on body weight gain and serum values

\begin{tabular}{|c|c|c|c|c|}
\hline Treatments & $\begin{array}{l}\text { Body weight } \\
\text { gain }\end{array}$ & Triglycerides & Cholesterol & Glucose \\
\hline $\mathrm{C}$ & $20 \cdot 3 \pm 4 \cdot 3$ & $174 \pm 26$ & $70 \pm 7$ & $167 \pm 15$ \\
\hline $\mathrm{D}$ & $33 \cdot 7 \pm 2 \cdot 6^{* *}$ & $266 \pm 38^{* *}$ & $74 \pm 19$ & $181 \pm 25$ \\
\hline DT & $24 \cdot 3 \pm 4 \cdot 9^{\#}$ & $191 \pm 57$ & $56 \pm 19$ & $166 \pm 17$ \\
\hline $\mathrm{CT}$ & $25 \cdot 8 \pm 4 \cdot 6^{\#}$ & $129 \pm 14$ & $73 \pm 7$ & $155 \pm 10$ \\
\hline
\end{tabular}

Twenty-four male Wistar rats were divided into four groups; serum concentrations of triglycerides, cholesterol and glucose were measured using a Hitachi 7170 mean serum values \pm s.D. of body weight gain $(\%)$ triglycerides, cholesterol and glucose $(\mathrm{mg} / \mathrm{dl})$ in standard diet-fed rats $(\mathrm{C})$, $\mathrm{HFD}$ (D), HFD $+\mathrm{T}_{2}$ (DT) and $C+\mathrm{T}_{2}(\mathrm{CT})$ rats. Significant differences are reported: $\mathrm{C}$ vs $\mathrm{D}\left({ }^{* *} P \leq 0 \cdot 01\right)$ and $\mathrm{D}$ vs $\mathrm{DT}$ or $\mathrm{D}$ vs $\mathrm{CT}\left({ }^{*} P \leq 0 \cdot 05\right)$.

HFD-fed rats treated with $\mathrm{T}_{2}$ (DT) and standard diet-fed rats treated with $\mathrm{T}_{2}$ (CT; Grasselli et al. 2008). D rats showed a significant increment in mean $\mathrm{BW}$ with respect to control (C) rats $(+13 \% ; P \leq 0 \cdot 01)$. Such an increase was prevented by $\mathrm{T}_{2}$ administration to $\mathrm{D}$ rats $(-28 \%$ with respect to $\mathrm{D}$ rats; $P \leq 0 \cdot 01)$. A marked increase in TAG levels $(+52 \% ; P \leq 0 \cdot 01)$ was observed in $D$ rats with respect to $C$ rats, while in DTand CT rats the values were similar to those of $\mathrm{C}$ rats. No changes in cholesterol, and glucose levels were detected in all experimental groups.

In this study, ORO staining of liver sections confirmed that HFD feeding (D rats) increased hepatic lipid accumulation with respect to controls (C), and this effect was prevented by simultaneous $\mathrm{T}_{2}$ administration (DT; Fig. 1A).

When liver histology was assessed by haematoxylin-eosin staining, the tissue of control rats (C) showed an array of wheel-shaped cells along the centrilobular vein, with a clear lobular structure, well-arranged hepatic cords and cells with round and central nuclei (Fig. 1B). No significant histological changes could be appreciated in different experimental conditions, including the HFD group, despite the increase in lipid accumulation.

Since fatty liver could be associated with inflammatory condition, the expression of interleukin $1 \beta$ (IL1 $\beta$ ) mRNA was assessed as a marker of liver inflammation. In liver of $D$ rats, a significant increase in IL1 $\beta$ mRNA expression was detected (about 2-2-fold induction with respect to C; $P \leq 0 \cdot 001$; Fig. 1C). Administration of $\mathrm{T}_{2}$ to $\mathrm{D}$ rats prevented the up-regulation of IL1 $\beta$ expression (about $1 \cdot 2$-fold induction with respect to $\mathrm{C},-50 \%$ with respect to $\mathrm{D}$ rats; $P \leq 0 \cdot 001)$. No changes in IL1 $\beta$ expression were observed in $\mathrm{CT}$ rats with respect to $\mathrm{C}$.

\section{Expression of PPARs}

The relative abundance of mRNA transcripts for PPAR $\alpha$, PPAR $\gamma$ and PPAR $\delta$ was assessed by RT-qPCR in the liver of control rats (Fig. 2A). The $\mathrm{C}_{\mathrm{q}}$ values were about $23 \cdot 6$ for $\operatorname{PPAR} \alpha, 25 \cdot 1$ for PPAR $\gamma$ and $25 \cdot 6$ for PPAR $\delta$, thus pointing at the following relative abundance of PPAR isoform mRNA in rat liver: $\operatorname{PPAR} \alpha>\operatorname{PPAR} \gamma \cong \operatorname{PPAR} \delta$, the last two differing only for $0.5 \mathrm{C}_{\mathrm{q}}$.

The liver of $\mathrm{D}$ rats exhibited a significant increase in the level of PPAR $\gamma$ transcripts (Fig. 2B) in comparison to controls (about $1 \cdot 8$-fold induction, $P \leq 0 \cdot 05$ ), and $\mathrm{T}_{2}$ administration to $\mathrm{D}$ rats (DT) resulted in a further increase in PPAR $\gamma$ mRNA expression (about 3·2-fold induction with respect to $\mathrm{C},+205 \%$ with respect to $\mathrm{D}$ rats; $P \leq 0 \cdot 001)$. By contrast, PPAR $\delta$ expression did not change significantly in the liver of D rats (Fig. 2B), but it was reduced in DT rats (about $0 \cdot 6$-fold induction with respect to $\mathrm{C},-41 \%$ with respect to $\mathrm{D}$ rat; $P \leq 0 \cdot 01)$.
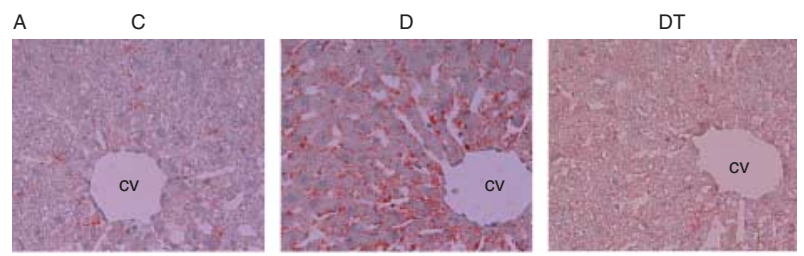

B
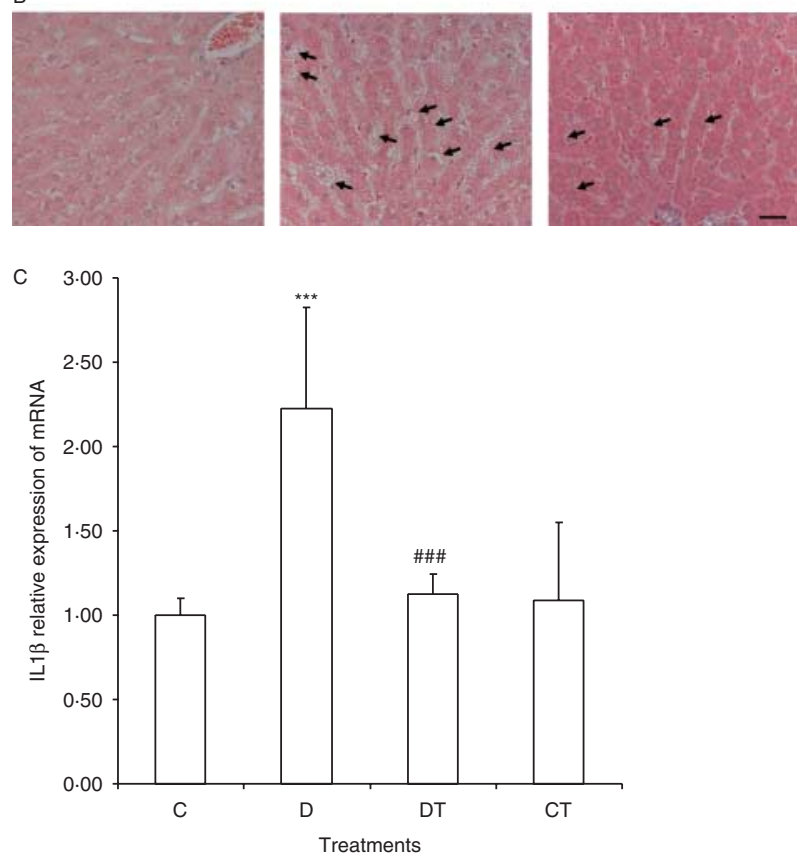

Figure 1 Effects of high-fat diet (HFD) and $T_{2}$ on rat liver. (A) Representative image of ORO-stained liver cryosections from standard diet-fed rats (C), HFD (D) and HFD $+\mathrm{T}_{2}$ (DT). Magnification $100 \times$; bar $=10 \mu \mathrm{m}$ (cv, centrilobular vein). (B) Haematoxylin-eosin staining of rat liver sections of standard diet-fed rats (C), HFD (D) and HFD $+\mathrm{T}_{2}$ (DT). Light microscopic images were acquired on the paraffin-embedded tissues. Magnification $40 \times$; bar $=30 \mu \mathrm{m}$; arrows indicate lipid droplets. (C) Relative mRNA expression of IL1 $\beta$ quantified by RT-qPCR in HFD (D), HFD $+\mathrm{T}_{2}$ (DT) and $\mathrm{C}+\mathrm{T}_{2}(\mathrm{CT})$ rats with respect to standard diet-fed rats (C). Data (mean \pm s.D.) are reported as fold induction with respect to controls after normalisation for GAPDH mRNA. Significant differences are reported: $C$ vs $D(* * * P \leq 0 \cdot 001)$ and $D$ vs DT $\left({ }^{\# \#} P \leq 0 \cdot 001\right)$. 
A
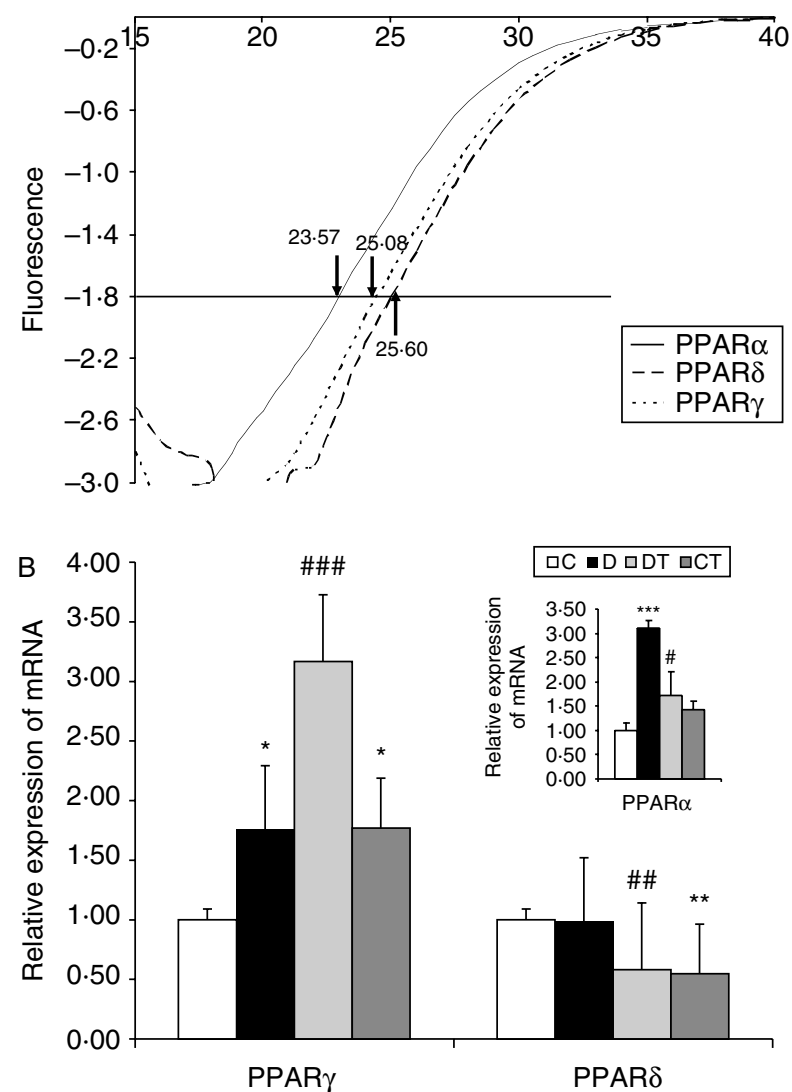

Figure 2 Effects of high-fat diet (HFD) and $T_{2}$ on hepatic expression of PPARs. (A) Relative abundance of the PPAR isoforms in the liver of control rats. The amplification curves of PPAR $\alpha, \operatorname{PPAR} \delta$ and PPAR $\gamma$ were acquired by RT-qPCR. $X$-axis, amplification cycle number and $Y$-axis, normalised fluorescence signal. (B) Relative mRNA expression of PPAR $\alpha$, PPAR $\gamma$ and PPAR $\delta$, and quantified by RT-qPCR in HFD (D), HFD $+\mathrm{T}_{2}(\mathrm{DT})$ and $\mathrm{C}+\mathrm{T}_{2}(\mathrm{CT})$ rats with respect to standard diet-fed rats $(\mathrm{C})$. Data (mean \pm s.D.) are reported as fold induction with respect to controls after normalisation for GAPDH mRNA. Significant differences are reported: C vs D or vs CT $(* * * P \leq 0 \cdot 001, * * P \leq 0 \cdot 01$ and $* P \leq 0 \cdot 05)$ and D vs DT $\left({ }^{\# \#} P \leq 0.001,{ }^{\#} P \leq 0.01\right.$ and $\left.{ }^{\#} P \leq 0.05\right)$.

Similar effects on PPAR expression were observed when $\mathrm{T}_{2}$ was administered to control rat (CT). In fact, $\mathrm{T}_{2}$ treatment resulted in up-regulation of PPAR $\gamma$ transcripts (about $1 \cdot 8$-fold induction with respect to $C ; P \leq 0 \cdot 05)$ and downregulation of PPAR $\delta$ expression (about $0 \cdot 5$-fold induction with respect to $\mathrm{C} ; P \leq 0 \cdot 01$ ).

The transcription profile of PPAR $\gamma$ showed a trend distinct form that previously observed for the lipolytic transcription factor PPAR $\alpha$ (inset in Fig. 2A; Grasselli et al. 2008). PPAR $\alpha$ transcription was in fact up-regulated in $\mathrm{D}$ rats (about $0 \cdot 3$-fold induction with respect to $C ; P \leq 0 \cdot 001$ ), and $T_{2}$ administration $(\mathrm{DT})$ prevented this up-regulation $(1 \cdot 7$-fold induction with respect to $\mathrm{C},-45 \%$ with respect to $\mathrm{D}$ rats; $P \leq 0 \cdot 05)$, but, differently from $\operatorname{PPAR} \gamma$, expression of PPAR $\alpha$ did not change in CT rats.
Expression of genes involved in lipid metabolism

Regarding the lipogenic pathways, transcription of the stearoyl-CoA desaturase ( $S C D-1)$, a desaturase that is required for the TAG synthesis, showed a significant decrease in the livers of $\mathrm{D}$ rats (about $0 \cdot 4$-fold induction with respect to $\mathrm{C}$; $P \leq 0.001$; Fig. 3A). Such a decrease was prevented by $T_{2}$ administration (DT; about $1 \cdot 0$-fold induction with respect to $\mathrm{C},+164 \%$ with respect to $\mathrm{D} ; P \leq 0 \cdot 001)$. $\mathrm{T}_{2}$ per se did not affect SCD-1 transcription in control rats (CT).

With regards to lipolytic pathways, the mRNA expression of the peroxisomal enzyme acyl-CoA oxidase (AOX) did not show a significant increase in D rats compared with controls (Fig. 3B). On the other hand, $\mathrm{T}_{2}$ administration to $\mathrm{D}$ rats induced a large increase in hepatic AOX mRNA levels (about $2 \cdot 8$-fold induction with respect to $\mathrm{C},+119 \%$ with respect to $\mathrm{D} ; P \leq 0 \cdot 01$ ), whereas $\mathrm{T}_{2}$ per se did not affect AOX expression in CT rats.

In the liver of $\mathrm{D}$ rats, a dramatic increase in mRNA expression of ATGL was detected (about $7 \cdot 7$-fold induction with respect to $C ; P \leq 0 \cdot 001$; Fig. $3 C$ ). Administration of $\mathrm{T}_{2}$ to $\mathrm{D}$ rats prevented the up-regulation of ATGL expression (about $0 \cdot 70$-fold induction with respect to C, $-91 \%$ with respect to $\mathrm{D}$ rats; $P \leq 0 \cdot 001)$. No changes in ATGL expression were observed in CT rats.

Expression of proteins involved in LD turnover and lipoprotein secretion

The liver of $\mathrm{D}$ rats showed a significant up-regulation of both ADRP and OXPAT mRNA expression (about 1.9-fold induction with respect to $\mathrm{C}, P \leq 0 \cdot 01$, for OXPAT; about $1 \cdot 6$-fold induction with respect to $\mathrm{C}, P \leq 0 \cdot 001$, for ADRP; Fig. 4A). This diet-induced up-regulation was prevented by $\mathrm{T}_{2}$ administration (DT; about 1.1-fold induction with respect to $\mathrm{C}$, for OXPAT; about $0 \cdot 8$-fold induction with respect to C, for ADRP; $-43 \% P \leq 0 \cdot 01$ and $-50 \% P \leq 0 \cdot 001$, respectively, with respect to $\mathrm{D})$. Conversely, neither HFD nor $T_{2}$, nor their combination significantly affected the mRNA expression of the other PAT protein TIP47.

As reported in Fig. 4B, the expression of FIT2, an ER resident protein involved in LD biogenesis, was not modified in D rats. However, FIT2 expression was significantly down-regulated both in DT (about 0.6-fold induction with respect to $\mathrm{C},-46 \%$ with respect to $\mathrm{D} ; P \leq 0 \cdot 001)$ and in CT (about 0.7-fold induction in CT with respect to C; $P \leq 0 \cdot 05)$ rats.

To better investigate alterations of hepatic LDs in the different experimental conditions, possible changes in their size and number were assessed by ADRP immunostaining (Fig. 4C). In liver of $\mathrm{C}$ rats, little or no ADRP staining was present in the hepatic lobules. By contrast, the liver of $\mathrm{D}$ rats exhibited numerous and large ADRP-positive vesicles that were preferentially located at the periphery of the cell. $\mathrm{T}_{2}$ administration to $\mathrm{D}$ rats prevented this accumulation of positive vesicles. 

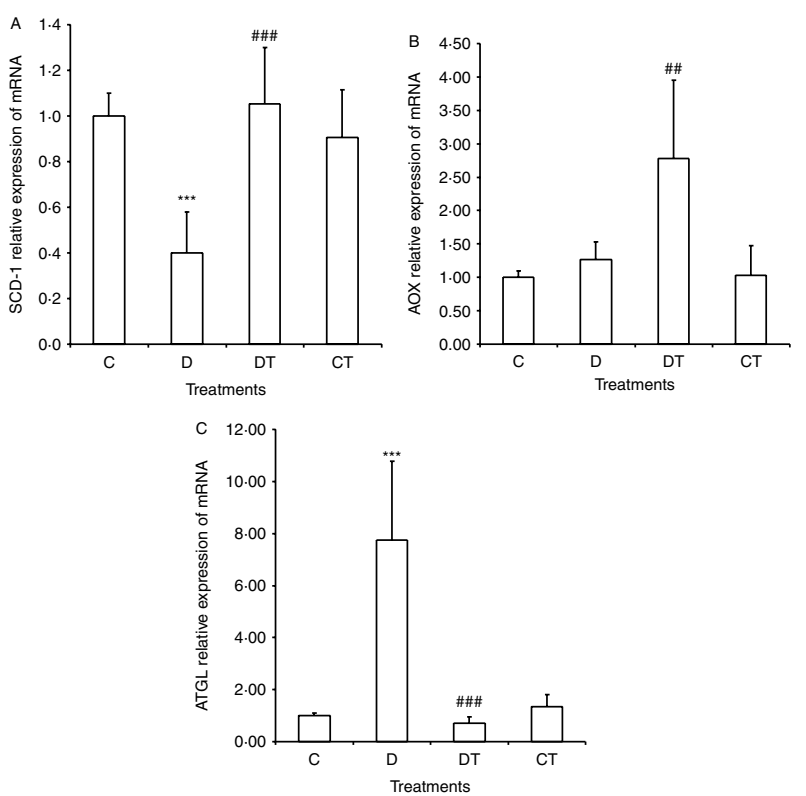

Figure 3 Effects of high-fat diet (HFD) and $\mathrm{T}_{2}$ on hepatic expression of genes involved in lipid metabolism. Relative mRNA expression of stearoyl-CoA desaturase (SCD-1) (A), acyl-CoA oxidase (AOX) (B) and adipose triglyceride lipase (ATGL) $(\mathrm{C})$ quantified by RT-qPCR in HFD (D), HFD $+T_{2}$ (DT) and $C+T_{2}$ (CT) rats with respect to standard diet-fed rats (C). Data (mean \pm s.D.) are reported as fold induction with respect to controls after normalisation for GAPDH mRNA. Significant differences are reported: $C$ vs $D$ or vs $C T$ $(* * * P \leq 0 \cdot 001)$ and D vs DT ( ${ }^{\# \#} P \leq 0 \cdot 001$ and $\left.{ }^{\#} P \leq 0 \cdot 01\right)$.

With regards to lipid secretion, the liver of $\mathrm{D}$ rats did not show significant changes in mRNA expression of apo B, the major protein component of VLDL (Fig. 4D). Administration of $\mathrm{T}_{2}$ to $\mathrm{D}$ rats up-regulated mRNA expression of apo $\mathrm{B}$ (about 1.7-fold induction with respect to $\mathrm{C}$, $+79 \%$ with respect to $\mathrm{D} ; P \leq 0 \cdot 001)$. No changes in apo $\mathrm{B}$ mRNA levels were observed in $\mathrm{CT}$ animals with respect to $\mathrm{C}$.

\section{Discussion}

In previous studies (Lanni et al. 2005, Grasselli et al. 2008), $\mathrm{T}_{2}$ administration was shown to prevent the HFD-induced BW gain and hepatic steatosis, as well as the oxidative stress associated with the fatty liver condition, thus suggesting the therapeutic potential role of $\mathrm{T}_{2}$ for preventing or treating steatosis (Mollica et al. 2009). In this study, the effects of $\mathrm{T}_{2}$ on the liver of rat fed HFD were examined by assessing the transcription profiles of some important genes involved in lipid metabolism.

As previously reported (Grasselli et al. 2008), histologically evident hepatic microvesicular steatosis was induced in HFD rats and the effect was prevented by concomitant $T_{2}$ administration. Typically, the excess fat accumulation stimulates FFA oxidation likely leading to oxidative stress that may induce the release of several pro-inflammatory cytokines (such as IL1 $\beta$ and IL6) by Kupffer cells and hepatocytes (Day 2006). Even if in our experimental model the increase in hepatic lipid accumulation was not associated with marked changes in the physiological morphology of the liver, a significant increase in transcription of IL1 $\beta$ was observed, indicating the initiation of inflammatory processes induced by diet. $\mathrm{T}_{2}$ administration to HFD rats not only prevented lipid accumulation, but also IL1 $\beta$ up-regulation.

In the liver of control rats, all PPAR isoforms are constitutively expressed, but PPAR $\alpha$ transcripts are more abundant than their $\operatorname{PPAR} \gamma$ and $\operatorname{PPAR} \delta$ counterparts. Associated with fat accumulation, the liver of $\mathrm{D}$ rats showed a large increase in expression of $\operatorname{PPAR} \alpha$, and a smaller increase in that of PPAR $\gamma$. This can be explained by the role of PPAR $\alpha$ in stimulating the activities of the FFA oxidation systems (Duval et al. 2007, Pyper et al. 2010) and of PPAR $\gamma$ in promoting fat accumulation in LDs (Gavrilova et al. 2003, Browning \& Horton 2004). By contrast, the excess fat did not significantly alter the hepatic expression of PPAR $\delta$.

Despite the increase in $\operatorname{PPAR} \alpha$ and PPAR $\gamma$ expression induced by diet, we observed a slight, but not significant increment in mRNA expression of the peroxisomal enzyme AOX, which is a target of both PPARs (Rogue et al. 2011). However, an increase in both activity (Grasselli et al. 2008) and protein level (Silvestri et al. 2010) of catalase in D rats was previously reported, suggesting that peroxisomal $\beta$-oxidation is stimulated as a response to HFD. Besides, other reports indicated that mitochondrial FFA oxidation is also widely involved in fat liver condition (Serviddio et al. 2008). The presence of an excess of fat in the liver induced a down-regulation of the lipogenic enzyme SCD-1 that is target of PPARs. Therefore, it is likely that the rat liver responds to the excess fat both by activating mechanisms of lipid storage and FFA oxidation, as well as by inhibiting pathways of lipid synthesis.

In association with its anti-steatotic effects, $\mathrm{T}_{2}$ prevented the HFD-induced up-regulation of $\operatorname{PPAR} \alpha$, further up-regulated expression of PPAR $\gamma$ and down-regulated expression of PPAR $\delta$. Moreover, $\mathrm{T}_{2}$ per se up-regulated PPAR $\gamma$ and down-regulated PPAR $\delta$ expression in the liver of CT rats, but it did not affect PPAR $\alpha$ expression. These results indicate that in rat liver, $\operatorname{PPAR} \gamma$ and $\operatorname{PPAR} \delta$ are direct targets for the action of $\mathrm{T}_{2}$.

The increased expression of PPAR $\gamma$ in liver of DT rats requires some further considerations. Although PPAR $\gamma$ is typically considered a key factor in regulation of lipogenesis, it is a pleiotropic transcription factor that regulates a variety of genes involved in virtually all pathways of lipid metabolism, including local FFA release from circulating lipoproteins (Schoonjans et al. 1996), FFA uptake (Motojima et al. 1998, Chui et al. 2005), FFA synthesis (Castelein et al. 1994, Jitrapakdee et al. 2005), LD stabilisation (Arimura et al. 2004, Schadinger et al. 2005) and also FFA oxidation (Bogacka et al. 2005). A recent study of comparative global gene expression profiles induced by PPAR $\gamma$ and dual PPAR $\alpha / \gamma$ agonists in rat hepatocytes showed that PPAR $\gamma$ shares many 

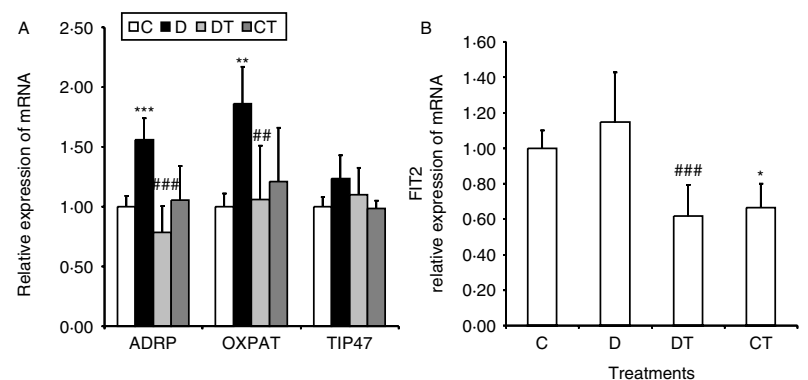

C
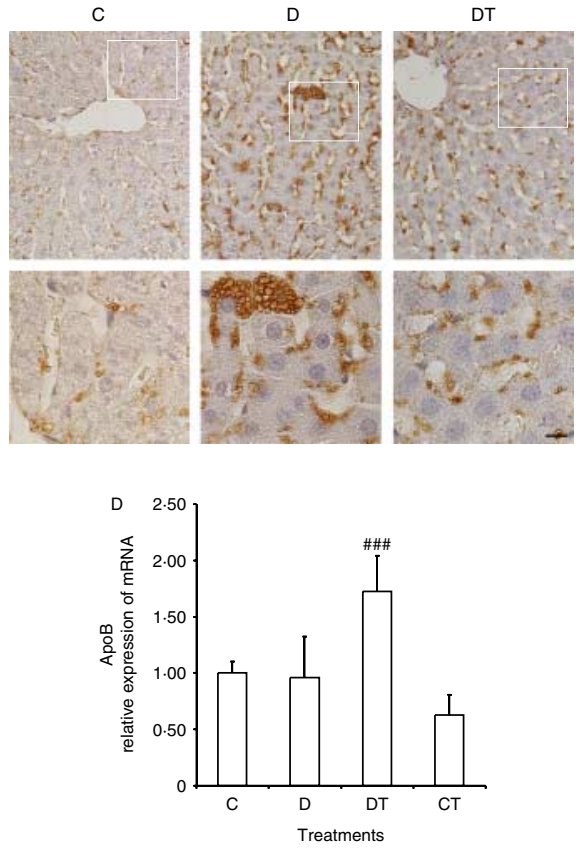

Figure 4 Effects of high-fat diet (HFD) and $T_{2}$ on expression genes involved in LD turnover and lipoprotein secretion. Relative mRNA expression of ADRP, OXPAT, TIP47 (A) and FIT2 (B), quantified by RT-qPCR in HFD (D), HFD $+\mathrm{T}_{2}$ (DT) and $\mathrm{C}+\mathrm{T}_{2}$ (CT) rats with respect to standard diet-fed rats $(\mathrm{C})$. Data (mean \pm s.D.) are reported as fold induction with respect to controls after normalisation for GAPDH mRNA. Significant differences are reported: $C$ vs D or vs CT $(* * * P \leq 0 \cdot 001, * * P \leq 0 \cdot 01$ and $* P \leq 0 \cdot 05)$ and $D$ vs DT ("\#\# $P \leq 0.001$ and $\left.{ }^{\#} P \leq 0 \cdot 01\right)$. (C) Immunohistochemical staining for ADRP of liver sections from standard diet-fed rats (C), HFD (D) and HFD $+\mathrm{T}_{2}$ (DT). Nuclear staining with haematoxylin is also shown. For each image, higher magnification of the framed area was presented below. Upper images: magnification $40 \times$; bar $=$ $30 \mu \mathrm{m}$. Lower images: magnification $100 \times$; bar $=10 \mu \mathrm{m}$. (D) Relative mRNA expression of apo B quantified by RT-qPCR in HFD (D), HFD $+\mathrm{T}_{2}$ (DT) and $\mathrm{C}+\mathrm{T}_{2}$ (CT) rats with respect to standard diet-fed rats $(C)$. Data (mean \pm s.D.) are reported as fold induction with respect to controls after normalisation for GAPDH mRNA. Significant differences are reported: D vs DT $\left({ }^{\# \#} P \leq 0 \cdot 001\right)$. Full colour version of this figure available via http://dx.doi.org/10.1530/ JOE-11-0288.

target genes with PPAR $\alpha$, including those involved in FFA oxidation (Rogue et al. 2011). Besides, PPAR $\gamma$ is the molecular target for anti-diabetic agents (that are synthetic PPAR $\gamma$ agonists) that lower the hepatic TAG content (Balasubramanian et al. 2010, Cheatham 2010). In conclusion, it is likely that PPAR $\gamma$ may increase both TAG hydrolysis and lipid synthesis, with the latter effecting predominating under most, but not all, conditions. Finally, PPAR $\gamma$ may play also a protective effect through its ability to reduce hepatic inflammatory responses in rats fed a high-cholesterol fructose diet (Collino et al. 2010).

$\mathrm{T}_{2}$ administration to HFD rats increased AOX expression also, but this effect was not observed in CT rats. This indicates that a stimulation of peroxisomal FFA oxidation occurs upon $\mathrm{T}_{2}$ administration, in addition to stimulation of the mitochondrial oxidative pathways (Mollica et al. 2009, Silvestri et al. 2010), in the attempt to reduce the excess fat. Moreover, the increased PPAR $\gamma$ levels are in accordance with an action of $\mathrm{T}_{2}$ in preventing the pro-inflammatory condition associated with the diet.

To further investigate the possible pathways supporting the anti-steatotic effects of $T_{2}$, we assessed the expression of genes regulating lipid accumulation within LDs and lipid secretion. Lipid overload is associated with modulation of expression of PAT proteins. ADRP, a well-known marker of steatosis, promotes the incorporation of lipids in LDs (Bickel et al. 2009); ADRP-containing large LDs represent, in fact, a relatively inert pool for long-term TAG storage (Wang et al. 2010). By contrast, TIP47 preferentially labels nascent LDs (Zimmermann et al. 2009) and binds LDs in response to lipid loading (Wolins et al. 2001), and the nascent TIP47containing small LDs may represent a metabolically active pool (Wang et al. 2010). On the other hand, OXPAT is postulated to regulate lipid storage for short-term utilisation through oxidative pathways and moves to the LD surface during lipid loading (Yamaguchi et al. 2006, Dalen et al. 2007, Bickel et al. 2009). Our results show a significant up-regulation of both ADRP and OXPAT mRNA expression in liver of $\mathrm{D}$ rats, and this up-regulation was prevented by $\mathrm{T}_{2}$ administration; these results are in accordance with the anti-steatotic effects above described for $T_{2}$. No significant changes were instead observed in TIP47 expression.

To visualise LD size and number in the different experimental conditions, ADRP immunostaining of liver sections was performed. As expected, ADRP-positive LDs were increased in number and size in $\mathrm{D}$ rats in comparison with $\mathrm{C}$ rats. $\mathrm{T}_{2}$ administration to $\mathrm{D}$ rats partially counteracted accumulation of ADRP-positive LDs.

Lipid stored in LDs can be mobilised by lipases as a response to external or internal stimuli. ATGL is considered the ratelimiting lipolytic enzyme in mammals (Haemmerle et al. 2006), and is a major TAG lipase in the liver where it acts, likely through PPAR $\alpha$, to channel hydrolyzed FFAs towards oxidative pathways as opposed to VLDL secretory pathways (Ong et al. 2011). In adipocytes, ATGL levels are increased by PPAR $\gamma$ agonists (Kershaw et al. 2007), while, in hepatocytes, ATGL overexpression is associated with increased catabolism of FFAs and stimulated PPAR $\alpha$ activity (Ong et al. 2011). In our study, we observed a large increase in ATGL mRNA expression in liver of $\mathrm{D}$ rats that indicates a stimulation of 
lipolytic pathways as a response to excess fat. Concomitant administration of $T_{2}$ to $\mathrm{D}$ rats prevented the up-regulation of ATGL expression. On the other hand, $\mathrm{T}_{2}$ per se did not affect ATGL expression and this suggests that the reduction in ATGL mRNA levels in DT rats may be a consequence of the reduced fat accumulation.

In addition to oxidation, in the liver the excess TAGs can be packaged into VLDL, which is exported in serum (Vance \& Vance 1990). In this regard, a crucial role is played by apo B, a lipid-binding protein that is used to assemble and stabilise the VLDL. In D rats, apo B expression did not change with respect to controls, but it was up-regulated upon $T_{2}$ administration (DT animals). Since in CTrats apo B expression was not affected, we can hypothesise that the effects of $T_{2}$ on apo $\mathrm{B}$ are strictly dependent on the excess fat in the liver, and that $\mathrm{T}_{2}$ may promote pathways leading to TAG mobilisation from LDs and secretion as VLDL. Studies are in progress to confirm an increment in VLDL secretion in hepatocytes overloaded of lipids and exposed to $\mathrm{T}_{2}$. Noteworthy, the modulation of apo $\mathrm{B}$ transcription fits well the pattern of ADRP expression that exhibits an opposite trend. In fact, the increase in ADRP expression detected in D rats may reduce the assembly of VLDL (Magnusson et al. 2006), while the lower ADRP expression in DT rats could be permissive for VLDL packaging driven by apo B overexpression.

In DT and CT rats, we also observed a decrease in the expression of FIT2, a membrane protein located in the ER, the site of TAG biosynthesis, and of LD biogenesis. Overexpression of FIT2 in mouse liver was reported to increase the LD number (Kadereit et al. 2008). Our results, showing a reduction in FIT2 expression upon $\mathrm{T}_{2}$ administration, support a role for $\mathrm{T}_{2}$ in promoting lipid secretion rather than accumulation.

Taken together, all these data suggest that $T_{2}$, in addition to induction of oxidative pathways, stimulates lipoprotein secretion to reduce the hepatic fat excess. However, serum TAGs, which are high in HFD-fed rats, appear to be normalised by $\mathrm{T}_{2}$ treatment, as previously reported by us and others (Lanni et al. 2005, Grasselli et al. 2008), so that an increase in trigliceridemia by $\mathrm{T}_{2}$ is not apparent, despite the possible stimulation of VLDL secretion. The VLDL receptor number is increased in the muscle of hyperthyroid rats (Jokinen et al. 1994), and TH administration increases serum levels of $T_{2}$ (Nishikawa et al. 1983). Therefore, it could be hypothesised that the increased rate of VLDL secretion induced by $T_{2}$ might be balanced by an increase in plasma VLDL removal rate by skeletal muscle, or other tissues. This point needs further investigation.

In conclusion, this study demonstrates that $T_{2}$ administration to HFD rats prevents most of the transcriptional changes of those genes that were modulated in response to the excess exogenous fat. In particular, $T_{2}$ prevents the pathways leading to the long-term TAG storage in LDs that were induced by HFD, and at the same time stimulates mechanisms of FFA oxidation and lipid secretion.

In summary, this study identifies some possible mechanisms underlying the improvement of the liver steatosis induced by $\mathrm{T}_{2}$.

\section{Declaration of interest}

The authors declare that there is no conflict of interest that could be perceived as prejudicing the impartiality of the research reported.

\section{Funding}

This study was supported by research grants from MIUR-COFIN 2008 (Prot. 20089SRS2X_002), Compagnia San Paolo (Torino) and University of Genoa.

\section{Acknowledgements}

Special thanks go to Andrea Compalati and Monika Schweier for their generous experimental activity. We also thank Mr V Capicchioni for his helpful technical assistance. Special thanks go to Prof. Emilia Fugassa for her critical reading of the manuscript and for the constant support and encouragement and to Dr Giorgio Filosa for his help with serum triglycerides, cholesterol and glucose content assessment.

\section{References}

Arimura N, Horiba T, Imagawa M, Shimizu M \& Sato R 2004 The peroxisome proliferator-activated receptor gamma regulates expression of the perilipin gene in adipocytes. Journal of Biological Chemistry 279 10070-10076. (doi:10.1074/jbc.M308522200)

Balasubramanian R, Gerrard J, Dalla MC, Firbank MJ, Lane A, English PT, Cobelli C \& Taylor R 2010 Combination peroxisome proliferator-activated receptor gamma and alpha agonist treatment in type 2 diabetes prevents the beneficial pioglitazone effect on liver fat content. Diabetic Medicine $\mathbf{2 7}$ 150-156. (doi:10.1111/j.1464-5491.2009.02906.x)

Bickel PE, Tansey JT \& Welte MA 2009 PAT proteins, an ancient family of lipid droplet proteins that regulate cellular lipid stores. Biochimica et Biophysica Acta 1791 419-440. (doi:10.1016/j.bbalip.2009.04.002)

Bogacka I, Xie H, Bray GA \& Smith SR 2005 Pioglitazone induces mitochondrial biogenesis in human subcutaneous adipose tissue in vivo. Diabetes 54 1392-1399. (doi:10.2337/diabetes.54.5.1392)

Browning JD \& Horton JD 2004 Molecular mediators of hepatic steatosis and liver injury. Journal of Clinical Investigation 114 147-152. (doi:10.1172/ JCI22422)

Bustin SA 2010 Why the need for qPCR publication guidelines? - the case for MIQE Methods 50 217-226. (doi:10.1016/j.ymeth.2009.12.006)

Castelein H, Gulick T, Declercq PE, Mannaerts GP, Moore DD \& Baes MI 1994 The peroxisome proliferator activated receptor regulates malic enzyme gene expression. Journal of Biological Chemistry $26926754-26758$.

Cheatham WW 2010 Peroxisome proliferator-activated receptor translational research and clinical experience. American Journal of Clinical Nutrition 91 262S-266S. (doi:10.3945/ajcn.2009.28449D)

Chui PC, Guan HP, Lehrke M \& Lazar MA 2005 PPARgamma regulates adipocyte cholesterol metabolism via oxidized LDL receptor 1. Journal of Clinical Investigation 115 2244-2256. (doi:10.1172/JCI24130)

Cimmino M, Mion F, Goglia F, Minaire Y \& Geloen A 1996 Demonstration of in vivo metabolic effects of 3,5-di-iodothyronine. Journal of Endocrinology 149 319-325. (doi:10.1677/joe.0.1490319)

Collino M, Aragno M, Castiglia S, Miglio G, Tomasinelli C, Boccuzzi G, Thiemermann C \& Fantozzi R 2010 Pioglitazone improves lipid and insulin levels in overweight rats on a high cholesterol and fructose diet by decreasing hepatic inflammation. British Journal of Pharmacology 160 1892-1902. (doi:10.1111/j.1476-5381.2010.00671.x)

Dalen KT, Dahl T, Holter E, Arntsen B, Londos C, Sztalryd C \& Nebb HI 2007 LSDP5 is a PAT protein specifically expressed in fatty acid oxidizing tissues. Biochimica et Biophysica Acta 1771 210-227. (doi:10.1016/j.bbalip. 2006.11.011) 
Day CP 2006 From fat to inflammation. Gastroenterology 130 207-210. (doi:10.1053/j.gastro.2005.11.017)

Delerive P, Fruchart JC \& Staels B 2001 Peroxisome proliferator-activated receptors in inflammation control. Journal of Endocrinology 169 453-459. (doi:10.1677/joe.0.1690453)

Ducharme NA \& Bickel PE 2008 Lipid droplets in lipogenesis and lipolysis. Endocrinology 149 942-949. (doi:10.1210/en.2007-1713)

Duncan RE, Ahmadian M, Jaworski K, Sarkadi-Nagy E \& Sul HS 2007 Regulation of lipolysis in adipocytes. Annual Review of Nutrition 27 79-101. (doi:10.1146/annurev.nutr.27.061406.093734)

Duval C, Muller M \& Kersten S 2007 PPARalpha and dyslipidemia. Biochimica et Biophysica Acta 1771 961-971. (doi:10.1016/j.bbalip.2007. 05.003)

Evans RM, Barish GD \& Wang YX 2004 PPARs and the complex journey to obesity. Nature Medicine 10 355-361. (doi:10.1038/nm1025)

Gavrilova O, Haluzik M, Matsusue K, Cutson JJ, Johnson L, Dietz KR, Nicol CJ, Vinson C, Gonzalez FJ \& Reitman ML 2003 Liver peroxisome proliferator-activated receptor gamma contributes to hepatic steatosis, triglyceride clearance, and regulation of body fat mass. Journal of Biological Chemistry 278 34268-34276. (doi:10.1074/jbc.M300043200)

Goglia F 2005 Biological effects of 3,5-diiodothyronine (T(2)). Biochemistry 70 $164-172$.

Grasselli E, Canesi L, Voci A, De Matteis R, Demori I, Fugassa E \& Vergani L 2008 Effects of 3,5-diiodo-L-thyronine administration on the liver of high fat diet-fed rats. Experimental Biology and Medicine 233 549-557. (doi:10. 3181/0710-RM-266)

Grasselli E, Voci A, Pesce C, Canesi L, Fugassa E, Gallo G \& Vergani L 2010 PAT protein mRNA expression in primary rat hepatocytes: effects of exposure to fatty acids. International Journal of Molecular Medicine $\mathbf{2 5}$ 505-512. (doi:10.3892/ijmm_00000370)

Grasselli E, Voci A, Canesi L, De Matteis R, Goglia F, Cioffi F, Fugassa E, Gallo G \& Vergani L 2011a Direct effects of iodothyronines on excess fat storage in rat hepatocytes. Journal of Hepatology 54 1230-1236. (doi:10. 1016/j.jhep.2010.09.027)

Grasselli E, Voci A, Canesi L, Goglia F, Ravera S, Panfoli I, Gallo G \& Vergani L $2011 b$ Non-receptor-mediated actions are responsible for the lipidlowering effects of iodothyronines in $\mathrm{FaO}$ rat hepatoma cells. Journal of Endocrinology 210 59-69. (doi:10.1530/JOE-11-0074)

Haemmerle G, Lass A, Zimmermann R, Gorkiewicz G, Meyer C, Rozman J, Heldmaier G, Maier R, Theussl C, Eder S et al. 2006 Defective lipolysis and altered energy metabolism in mice lacking adipose triglyceride lipase. Science 312 734-737. (doi:10.1126/science.1123965)

Hsu SM, Raine L \& Fanger H 1981 Use of avidin-biotin-peroxidase complex $(\mathrm{ABC})$ in immunoperoxidase techniques: a comparison between $\mathrm{ABC}$ and unlabeled antibody (PAP) procedures. Journal of Histochemistry and Cytochemistry 29 577-580. (doi:10.1177/29.4.6166661)

Jitrapakdee S, Slawik M, Medina-Gomez G, Campbell M, Wallace JC, Sethi JK, O'rahilly S \& Vidal-Puig AJ 2005 The peroxisome proliferator-activated receptor-gamma regulates murine pyruvate carboxylase gene expression in vivo and in vitro. Journal of Biological Chemistry 280 27466-27476. (doi:10.1074/jbc.M503836200)

Jokinen EV, Landschulz KT, Wyne KL, Ho YK, Frykman PK \& Hobbs HH 1994 Regulation of the very low density lipoprotein receptor by thyroid hormone in rat skeletal muscle. Journal of Biological Chemistry 269 26411-26418.

Kadereit B, Kumar P, Wang WJ, Miranda D, Snapp EL, Severina N, Torregroza I, Evans T \& Silver DL 2008 Evolutionarily conserved gene family important for fat storage. PNAS 105 94-99. (doi:10.1073/pnas. 0708579105)

Kapadia R, Yi JH \& Vemuganti R 2008 Mechanisms of anti-inflammatory and neuroprotective actions of PPAR-gamma agonists. Frontiers in Bioscience 13 1813-1826. (doi:10.2741/2802)

Kershaw EE, Schupp M, Guan HP, Gardner NP, Lazar MA \& Flier JS 2007 PPARgamma regulates adipose triglyceride lipase in adipocytes in vitro and in vivo. American Journal of Physiology. Endocrinology and Metabolism 293 E1736-E1745. (doi:10.1152/ajpendo.00122.2007)
Kimmel AR, Brasaemle DL, McAndrews-Hill M, Sztalryd C \& Londos C 2010 Adoption of PERILIPIN as a unifying nomenclature for the mammalian PAT-family of intracellular lipid storage droplet proteins. Journal of Lipid Research 51 468-471. (doi:10.1194/jlr.R000034)

Koopman R, Schaart G \& Hesselink MK 2001 Optimisation of oil red O staining permits combination with immunofluorescence and automated quantification of lipids. Histochemistry and Cell Biology 116 63-68. (doi:10. 1007/s004180100297)

Lanni A, Moreno M, Lombardi A \& Goglia F 1994 Rapid stimulation in vitro of rat liver cytochrome oxidase activity by 3,5-diiodo-L-thyronine and by 3,3'-diiodo-L-thyronine. Molecular and Cellular Endocrinology 99 89-94. (doi:10.1016/0303-7207(94)90150-3)

Lanni A, Moreno M, Lombardi A, de Lange P, Silvestri E, Ragni M, Farina P, Baccari GC, Fallahi P, Antonelli A et al. 2005 3,5-Diiodo-L-thyronine powerfully reduces adiposity in rats by increasing the burning of fats. FASEB Journal 19 1552-1554. (doi:10.1096/fj.05-3977fje)

Lombardi A, Lanni A, Moreno M, Brand MD \& Goglia F 1998 Effect of 3,5di-iodo-L-thyronine on the mitochondrial energy-transduction apparatus. Biochemical Journal 330 521-526.

Lombardi A, Lanni A, de Lange P, Silvestri E, Grasso P, Senese R, Goglia F \& Moreno M 2007 Acute administration of 3,5-diiodo-L-thyronine to hypothyroid rats affects bioenergetic parameters in rat skeletal muscle mitochondria. FEBS Letters $\mathbf{5 8 1}$ 5911-5916. (doi:10.1016/j.febslet.2007. 11.073)

Magnusson B, Asp L, Bostrom P, Ruiz M, Stillemark-Billton P, Linden D, Boren J \& Olofsson SO 2006 Adipocyte differentiation-related protein promotes fatty acid storage in cytosolic triglycerides and inhibits secretion of very low-density lipoproteins. Arteriosclerosis, Thrombosis, and Vascular Biology 26 1566-1571. (doi:10.1161/01.ATV.0000223345. 11820.da)

Mollica MP, Lionetti L, Moreno M, Lombardi A, de Lange P, Antonelli A, Lanni A, Cavaliere G, Barletta A \& Goglia F 2009 3,5-Diiodo-L-thyronine, by modulating mitochondrial functions, reverses hepatic fat accumulation in rats fed a high-fat diet. Journal of Hepatology 51 363-370. (doi:10.1016/j. jhep.2009.03.023)

Moreno M, Lanni A, Lombardi A \& Goglia F 1997 How the thyroid controls metabolism in the rat: different roles for triiodothyronine and diiodothyronines. Journal of Physiology 505 529-538. (doi:10.1111/j.1469-7793.1997. 529bb.x)

Motojima K, Passilly P, Peters JM, Gonzalez FJ \& Latruffe N 1998 Expression of putative fatty acid transporter genes are regulated by peroxisome proliferator-activated receptor alpha and gamma activators in a tissue- and inducer-specific manner. Journal of Biological Chemistry 273 16710-16714. (doi:10.1074/jbc.273.27.16710)

Musso G, Gambino R \& Cassader M 2009 Recent insights into hepatic lipid metabolism in non-alcoholic fatty liver disease (NAFLD). Progress in Lipid Research 48 1-26. (doi:10.1016/j.plipres.2008.08.001)

Nishikawa M, Inada M, Naito K, Ishii H, Tanaka K, Mashio Y \& Imura H 1983 Serum concentrations of 3, 3'-diiodothyronine, 3', 5'-diiodothyronine, and 3, 5-diiodothyronine in altered thyroid states. Endocrinologia Japonica 30 167-172. (doi:10.1507/endocrj1954.30.167)

Olofsson SO, Bostrom P, Andersson L, Rutberg M, Perman J \& Boren J 2009 Lipid droplets as dynamic organelles connecting storage and efflux of lipids. Biochimica et Biophysica Acta 1791 448-458. (doi:10.1016/j. bbalip.2008.08.001)

Ong KT, Mashek MT, Bu SY, Greenberg AS \& Mashek DG 2011 Adipose triglyceride lipase is a major hepatic lipase that regulates triacylglycerol turnover and fatty acid signaling and partitioning. Hepatology $\mathbf{5 3}$ 116-126. (doi:10.1002/hep.24006)

Pfaffl MW 2001 A new mathematical model for relative quantification in real-time RT-PCR. Nucleic Acids Research 29 e45. (doi:10.1093/nar/ 29.9.e45)

Pyper SR, Viswakarma N, Yu S \& Reddy JK 2010 PPARalpha: energy combustion, hypolipidemia, inflammation and cancer. Nuclear Receptor Signaling 8 e002. (doi:10.1621/nrs.08002)

Reddy JK 2001 Nonalcoholic steatosis and steatohepatitis. III. Peroxisomal beta-oxidation, PPAR alpha, and steatohepatitis. American Journal of Physiology. Gastrointestinal and Liver Physiology 281 G1333-G1339. 
Reid BN, Ables GP, Otlivanchik OA, Schoiswohl G, Zechner R, Blaner WS, Goldberg IJ, Schwabe RF, Chua SC Jr \& Huang LS 2008 Hepatic overexpression of hormone-sensitive lipase and adipose triglyceride lipase promotes fatty acid oxidation, stimulates direct release of free fatty acids, and ameliorates steatosis. Journal of Biological Chemistry 283 13087-13099. (doi:10.1074/jbc.M800533200)

Rogue A, Renaud MP, Claude N, Guillouzo A \& Spire C 2011 Comparative gene expression profiles induced by PPARgamma and PPARalpha/gamma agonists in rat hepatocytes. Toxicology and Applied Pharmacology 254 18-31. (doi:10.1016/j.taap.2011.04.005)

Romero Mdel M, Fernández-López JA, Esteve M \& Alemany M 2009 Oleoyl-oestrone inhibits lipogenic, but maintains thermogenic, gene expression of brown adipose tissue in overweight rats. Bioscience Reports 29 237-243. (doi:10.1042/BSR20080089)

Schadinger SE, Bucher NL, Schreiber BM \& Farmer SR 2005 PPARgamma2 regulates lipogenesis and lipid accumulation in steatotic hepatocytes. American Journal of Physiology. Endocrinology and Metabolism 288 E1195-E1205. (doi:10.1152/ajpendo.00513.2004)

Schoonjans K, Peinado-Onsurbe J, Lefebvre AM, Heyman RA, Briggs M, Deeb S, Staels B \& Auwerx J 1996 PPARalpha and PPARgamma activators direct a distinct tissue-specific transcriptional response via a PPRE in the lipoprotein lipase gene. EMBO Journal 15 5336-5348.

Serviddio G, Bellanti F, Tamborra R, Rollo T, Romano AD, Giudetti AM, Capitanio N, Petrella A, Vendemiale G \& Altomare E 2008 Alterations of hepatic ATP homeostasis and respiratory chain during development of non-alcoholic steatohepatitis in a rodent model. European Journal of Clinical Investigation 38 245-252. (doi:10.1111/ j.1365-2362.2008.01936.x)

Silvestri E, Cioffi F, Glinni D, Ceccarelli M, Lombardi A, de Lange P, Chambery A, Severino V, Lanni A, Goglia F et al. 2010 Pathways affected by 3,5-diiodo-L-thyronine in liver of high fat-fed rats: evidence from two-dimensional electrophoresis, blue-native PAGE, and mass spectrometry. Molecular Biosystems 6 2256-2271. (doi:10.1039/ c0mb00040j)

Spann NJ, Kang S, Li AC, Chen AZ, Newberry EP, Davidson NO, Hui ST \& Davis RA 2006 Coordinate transcriptional repression of liver fatty acidbinding protein and microsomal triglyceride transfer protein blocks hepatic very low density lipoprotein secretion without hepatosteatosis. Journal of Biological Chemistry 281 33066-33077. (doi:10.1074/jbc.M607148200)

Straus DS \& Glass CK 2007 Anti-inflammatory actions of PPAR ligands: new insights on cellular and molecular mechanisms. Trends in Immunology 28 551-558. (doi:10.1016/j.it.2007.09.003)

Sun J, Zhang C, Chen H, Fang X, Jin Q, Chen D, Shi X \& Du Y 2010 Two novel SNPs in coding region of the caprine fat-inducing transcript gene and their association with growth traits. Molecular Biology Reports 37 485-490. (doi:10.1007/s11033-009-9672-6)
Unger RH, Clark GO, Scherer PE \& Orci L 2010 Lipid homeostasis, lipotoxicity and the metabolic syndrome. Biochimica et Biophysica Acta 1801 209-214. (doi:10.1016/j.bbalip.2009.10.006)

Vance JE \& Vance DE 1990 Lipoprotein assembly and secretion by hepatocytes. Annual Review of Nutrition 10 337-356. (doi:10.1146/annurev. nu.10.070190.002005)

Vergani L, Lanza C, Rivaro P, Abelmoschi ML, Shyti G, Veneselli E, Minniti G, Grasselli E, Canesi L \& Voci A 2011 Metals, metallothioneins and oxidative stress in blood of autistic children. Research in Autism Spectrum Disorders 5 286-293. (doi:10.1016/j.rasd.2010.04.010)

Viswakarma N, Jia Y, Bai L, Vluggens A, Borensztajn J, Xu J \& Reddy JK 2010 Coactivators in PPAR-regulated gene expression. PPAR Research 2010 (doi:10.1155/2010/250126)

Wanders RJ, Ferdinandusse S, Brites P \& Kemp S 2010 Peroxisomes, lipid metabolism and lipotoxicity. Biochimica et Biophysica Acta 1801 272-280. (doi:10.1016/j.bbalip.2010.01.001)

Wang H, Wei E, Quiroga AD, Sun X, Touret N \& Lehner R 2010 Altered lipid droplet dynamics in hepatocytes lacking triacylglycerol hydrolase expression. Molecular Biology of the Cell 21 1991-2000. (doi:10.1091/mbc. E09-05-0364)

Wolins NE, Rubin B \& Brasaemle DL 2001 TIP47 associates with lipid droplets. Journal of Biological Chemistry 276 5101-5108. (doi:10.1074/jbc. M006775200)

Yamaguchi T, Matsushita S, Motojima K, Hirose F \& Osumi T 2006 MLDP, a novel PAT family protein localized to lipid droplets and enriched in the heart, is regulated by peroxisome proliferator-activated receptor alpha. Journal of Biological Chemistry 281 14232-14240. (doi:10.1074/jbc. M601682200)

Zechner R, Kienesberger PC, Haemmerle G, Zimmermann R \& Lass A 2009 Adipose triglyceride lipase and the lipolytic catabolism of cellular fat stores. Journal of Lipid Research 50 3-21. (doi:10.1194/jlr.R800031JLR200)

Zimmermann R, Lass A, Haemmerle G \& Zechner R 2009 Fate of fat: the role of adipose triglyceride lipase in lipolysis. Biochimica et Biophysica Acta 1791 494-500. (doi:10.1016/j.bbalip.2008.10.005)

Zivkovic AM, German JB \& Sanyal AJ 2007 Comparative review of diets for the metabolic syndrome: implications for nonalcoholic fatty liver disease. American Journal of Clinical Nutrition 86 285-300.

Received in final form 16 November 2011

Accepted 22 November 2011

Made available online as an Accepted Preprint

22 November 2011 